\title{
Chondrosarcoma of the Nasal Septum: A Case Report
}

\author{
Sahil Maingi B. Vageesh Padiyar Nishi Sharma \\ Department of Otorhinolaryngology, Dr. Ram Manohar Lohia Hospital, New Delhi, India
}

\section{Keywords}

Chondroma $\cdot$ Chondrosarcoma $\cdot$ Endoscopic excision

\begin{abstract}
Chondrosarcoma of the nasal septum is a rare entity with 5-10\% arising from the head and neck region. Differentiating benign cartilaginous tumors such as chondromas from low-grade chondrosarcomas can be challenging. We report a 45-year-old female who presented to us with bilateral nasal obstruction. A contrast-enhanced computed tomography and multiple deep biopsies were performed which were suggestive of grade 1 chondrosarcoma. The patient subsequently underwent endoscopic excision of the tumor with adequate margins confirmed by histopathology. The patient is on regular follow-up and has shown no evidence of recurrence on diagnostic nasal endoscopy and radiological imaging.

(C) 2019 The Author(s)

Published by S. Karger AG, Basel
\end{abstract}

\section{Introduction}

Chondrosarcomas are rare tumors known to arise from cartilage, 5-10\% arising from the head and neck region and laryngeal cartilage being the most predominant site of origin $[1,2]$. Surgery is considered as the primary treatment for chondrosarcoma. However, due to considerable risk of morbidity and unavoidable cosmetic problems, open approaches are avoided unless indicated. Endoscopic removal should be considered in cases when the tumor is limited to the nasal cavity. A review of the literature from 1927 to date lists approximately 63 cases of chondrosarcoma originating from the nasal septum [3].

\section{Case Report}

A 42-year-old woman presented with a 5-month history of bilateral nasal obstruction (left > right), persistent headache, anosmia, and left epiphora. There was no history of nasal discharge, epistaxis, loss of vision, diplopia, facial pain, facial swelling, fever, or weight loss. There was no similar history in the family. Nasal endoscopy revealed the presence of a firm, smooth, fleshy nontender intranasal mass filling both the nasal cavities. The mass did not bleed on touch and could not be separated from the adjacent septum. The nasopharynx appeared normal with patent eustachian tube bilaterally. Intraorally, there was a bulge over the hard palate (left > right) which was covered by normal mucosa. Her ocular movements were normal and otoscopic examination was unremarkable. There were no palpable cervical lymph nodes. General and systemic examinations were normal.

Contrast-enhanced CT scan of the nasal cavity and paranasal sinuses revealed a minimally enhancing homogenous soft tissue mass in the left nasal cavity, filling the anterior part of the nasal cavity with thinning of the left lateral nasal wall and extension into the right nasal cavity (Fig. 1). Posteriorly, the bony septum was intact. There was no evidence of bone destruction. No intratumor-

\begin{tabular}{ll}
\hline KARGER & $\begin{array}{l}\text { ( ) } 2019 \text { The Author(s) } \\
\text { Published by S. Karger AG, Basel Openger }\end{array}$ \\
E-Mail karger@karger.com & $\begin{array}{l}\text { This article is licensed under the Creative Commons Attribution- } \\
\text { NonCommercial-NoDerivatives 4.0 International License (CC BY- } \\
\text { www.karger.com/dmj }\end{array}$ \\
$\begin{array}{l}\text { NC-ND) (http://www.karger.com/Services/OpenAccessLicense). } \\
\text { Usage and distribution for commercial purposes as well as any dis- } \\
\text { tribution of modified material requires written permission. }\end{array}$
\end{tabular}

Dr B. Vageesh Padiyar

Dr. Ram Manohar Lohia Hospital

Baba Karak Singh Marg

New Delhi 110001 (India)

E-Mail gpadiyar@hotmail.com 

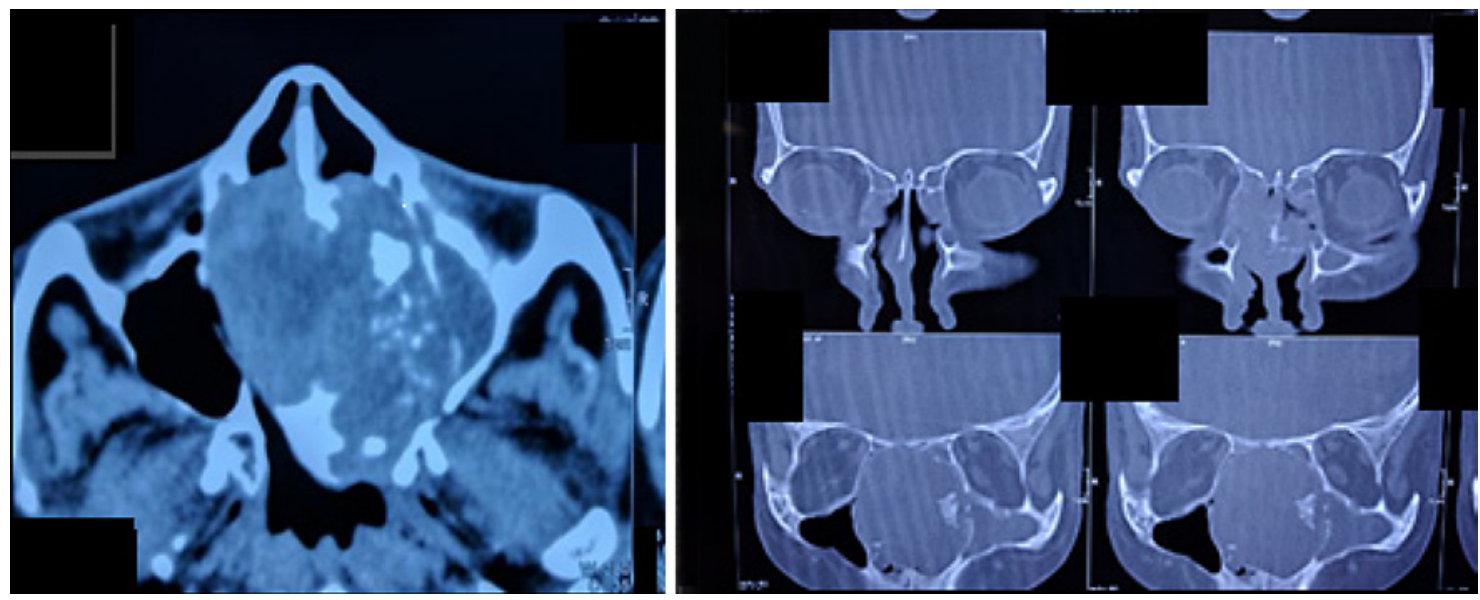

Fig. 1. Contrast-enhanced CT scan of the nose and paranasal sinus (axial and coronal sections) illustrating the extensions in the nasal cavity.

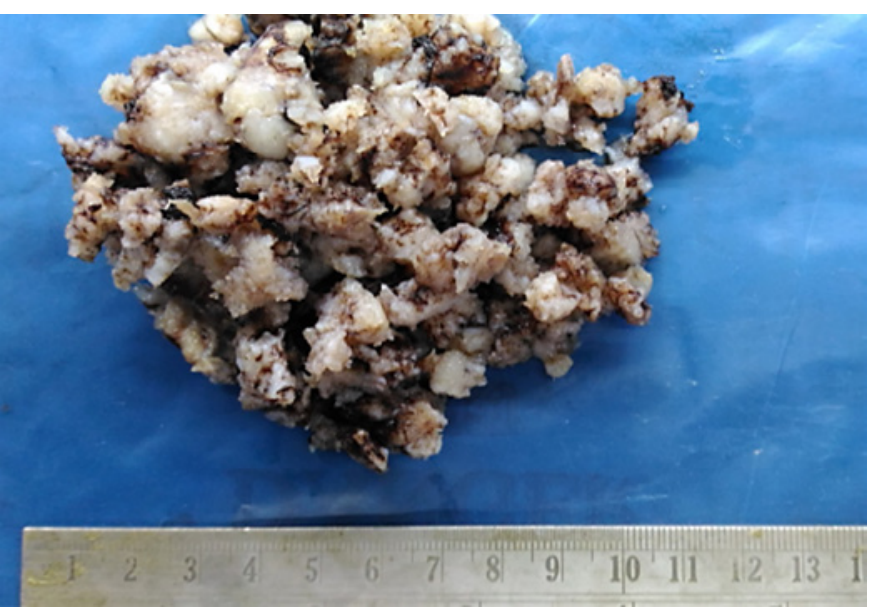

Fig. 2. Endoscopically excised specimen.

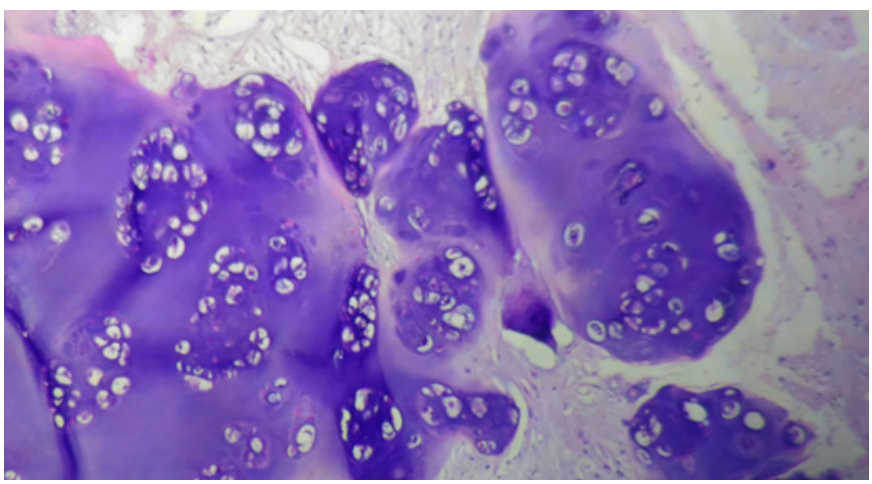

Fig. 3. Biopsy: fragments of cartilaginous tissue comprising lobules of chondrocytes embedded in chondroid matrix. H\&E. $\times 400$.

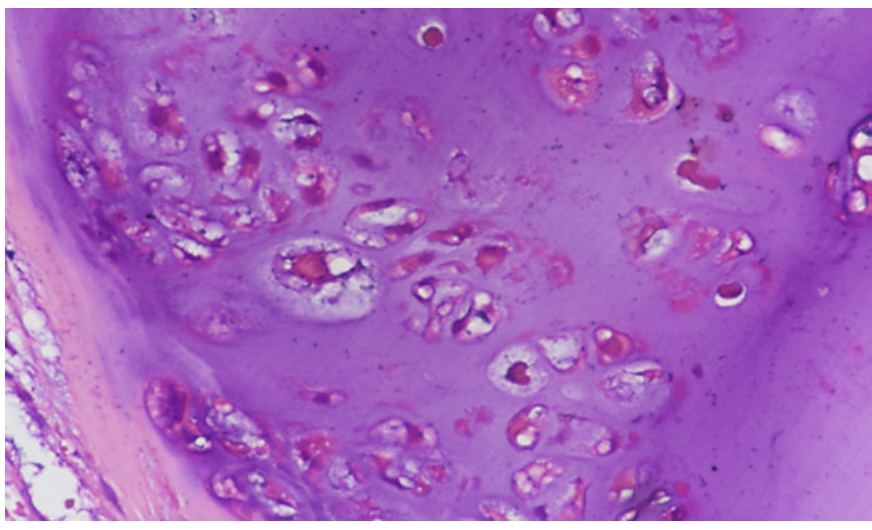

Fig. 4. Biopsy: fibroconnective stroma showing focal invasion by neoplastic chondrocytes which show mild to moderate pleomorphism with enlarged nuclei and mild hyperchromasia. H\&E. $\times 400$.

al calcification, local tissue destruction, or cervical lymphadenopathy was noted. Multiple endoscopic biopsies from the mass were performed under local anesthesia. Endoscopic excision of the nasal mass was done under general anesthesia (Fig. 2).

Histopathology revealed cartilaginous tissue comprising lobules of chondrocytes embedded in chondroid matrix with intervening fibroconnective tissue (Fig. 3). The lobules were moderately cellular composed of chondrocytes in groups as well as singly scattered. The chondrocytes showed mild to moderate pleomorphism, enlarged nuclei, and hyperchromasia. The fibroconnective stroma showed focal invasion by the neoplastic chondrocytes suggesting the possibility of grade 1 chondrosarcoma (Fig. 4). The patient had a satisfactory cosmetic outcome and did not require any surgical reconstruction. The patient is under follow-up every 6 months for the past 1 year and 5 months with no evidence of recurrence on diagnostic nasal endoscopy. 


\section{Discussion}

Chondrosarcomas are nonepithelial malignant tumors most commonly involving the pelvis, femur, and humerus with only 5-10\% located in the head and neck, most commonly in the larynx, maxilla, mandible, and skull base $[2,4,5]$. The usual age of presentation varies between 40 and 50 years, with higher incidence among men [6].

The diagnosis of chondrosarcomas is made histologically, and they are categorized into three grades on the basis of the degree of cellularity, nuclear size and atypia, and mitotic activity. Grade 1 chondrosarcomas have abundant chondroid matrix, clusters of chondrocytes with normal or slightly enlarged nuclei, rare nucleoli, absent mitoses, and occasional binucleation. Grade 2 chondrosarcomas, on the other hand, appear to have less chondroid matrix and more chondrocytes than grade 1 tumors with presence of rare mitoses, slightly enlarged vesicular hyperchromatic nuclei, and multinucleation. Grade 3 chondrosarcomas display a myxoid matrix with irregularly shaped chondrocytes and increased cellularity, nuclear pleomorphism, and mitoses compared with the low-grade chondrosarcomas $[2,7]$.

Head and neck chondrosarcomas may be initially misdiagnosed as chondromas due to sampling errors, making the diagnosis difficult [8]. Gallagher and Strome [9] in 1972 stressed the need for several intranasal biopsies to confirm the diagnosis of sarcoma.

F-18 fluoro-2-deoxyglucose positron emission tomography $\left({ }^{18} \mathrm{~F}-\mathrm{FDG}\right.$ PET) has been reported to help in cartilaginous tumor grading and outcome prediction. When the maximum SUV cutoff of 2.0 was used to distinguish benign and malignant cartilage neoplasms in 26 operated cartilaginous tumors, the sensitivity of ${ }^{18} \mathrm{~F}-$ FDG PET was $90.9 \%$, specificity $100 \%$, and accuracy $96.6 \%[10]$.

Chondrosarcomas are known to be relatively radioresistant, making surgery the primary option for treatment. Extensive disease warrants en bloc removal by open approaches which include lateral rhinotomy, anterior craniofacial resection, and Le Fort I down fracture. We chose transnasal endoscopic removal of the tumor, considering the mass was restricted within the nasal cavity, with safe resectable margins and a low rate of distant metastasis (low-grade chondrosarcoma).

To enhance radiosensitivity of grade II chondrosarcomas and to enhance the synergistic effect on apoptosis of the tumor, dual gene slicing technology has been implemented [11]. Some oncological institutes have imple- mented proton and carbon ion radiation in the treatment of chondrosarcoma considering its high local control, excellent precision, rapid delivery of high radiation doses, and low toxicity $[12,13]$.

\section{Conclusion}

A rare case of nasal septum chondrosarcoma was successfully treated by endoscopic nasal surgery. This approach could represent a safe and potentially curative treatment for this malignant tumor. We believe that transnasal endoscopic removal for this type of tumor should be implemented as a primary option in the future, even for more extensive cases.

\section{Statement of Ethics}

The research was conducted ethically in accordance with the World Medical Association Declaration of Helsinki. The subject gave written informed consent to publish her case (including publication of images).

\section{Disclosure Statement}

The authors have no conflicts of interest to declare.

\section{Funding Sources}

No funding was received for this study.

References

1 Downey TJ, Clark SK, Moore DW. Chondrosarcoma of the nasal septum. Otolaryngol Head Neck Surg. 2001 Jul;125(1):98-100.

2 Thompson LD, Gannon FH. Chondrosarcoma of the larynx: a clinicopathologic study of 111 cases with a review of the literature. Am J Surg Pathol. 2002 Jul;26(7):836-51.

3 Belgioia L, Vaccara EM, Bacigalupo A, Corvò R. Management of Nasal Septum Chondrosarcoma Occurring in Elderly: A Case Report. Cureus. 2017 Jul;9(7):e1497.

4 Evans HL, Ayala AG, Romsdahl MM. Prognostic factors in chondrosarcoma of bone: a clinicopathologic analysis with emphasis on histologic grading. Cancer. 1977 Aug;40(2): 818-31.

5 Ollivier L, Vanel D, Leclère J. Imaging of chondrosarcomas. Cancer Imaging. 2003 Oct;4(1):36-8. 
6 Bulut F, Kizilay A, Aydin NE. Chondrosarcoma of the nasal septum: a case report. Kulak Burun Bogaz Ihtis Derg. 2004;12(1-2):39-41.

7 Rassekh CH, Nuss DW, Kapadia SB, Curtin HD, Weissman JL, Janecka IP. Chondrosarcoma of the nasal septum: skull base imaging and clinicopathologic correlation. Otolaryngol Head Neck Surg. 1996 Jul;115(1):29-37.

8 Yamamoto S, Motoori K, Takano H, Nagata $\mathrm{H}$, Ueda T, Osaka I. Chondrosarcoma of the nasal septum. Skeletal Radiol. 2002 Sep;31(9): 543-6.
9 Gallagher TM, Strome M. Chondrosarcomas of the facial region. Laryngoscope. 1972 Jun; 82(6):978-84.

10 Lee DH, Jung SH, Yoon TM, Lee JK, Joo YE, Lim SC. Low grade chondrosarcoma of the nasal septum. World J Clin Cases. 2013 Apr; 1(1):64-6.

11 Kim DW, Seo SW, Cho SK, Chang SS, Lee HW, Lee SE, et al. Targeting of cell survival genes using small interfering RNAs (siRNAs) enhances radiosensitivity of Grade II chondrosarcoma cells. J Orthop Res. 2007 Jun; 25(6):820-8.
12 Ares C, Hug EB, Lomax AJ, Bolsi A, Timmermann B, Rutz HP, et al. Effectiveness and safety of spot scanning proton radiation therapy for chordomas and chondrosarcomas of the skull base: first long-term report. Int J Radiat Oncol Biol Phys. 2009 Nov; 75(4):1111-8.

13 Schulz-Ertner D, Nikoghosyan A, Hof H, Didinger B, Combs SE, Jäkel O, et al. Carbon ion radiotherapy of skull base chondrosarcomas. Int J Radiat Oncol Biol Phys. 2007 Jan; 67(1):171-7. 